\title{
Efficiency of Different Electrolytes on Electrochemical Chloride Extraction to Recover Concrete Structures under Chloride-Induced Corrosion
}

\author{
Thamara Tofeti Lima (iD) and Ki Yong Ann \\ Department of Civil and Environmental System Engineering, Hanyang University, Ansan 15888, Republic of Korea \\ Correspondence should be addressed to Ki Yong Ann; kann@hanyang.ac.kr
}

Received 21 April 2020; Accepted 23 June 2020; Published 15 July 2020

Guest Editor: Adriana Estokova

Copyright ( 2020 Thamara Tofeti Lima and Ki Yong Ann. This is an open access article distributed under the Creative Commons Attribution License, which permits unrestricted use, distribution, and reproduction in any medium, provided the original work is properly cited.

\begin{abstract}
Chloride-induced corrosion is one of the main causes of concrete deterioration and imposes a challenge to sustainability. Traditional techniques to repair corroded structures consisted of basically removing the damaged area, which was either economical or sustainable. Therefore, electrochemical chloride extraction (ECE) gained popularity for being an efficient nondestructive treatment applied temporarily to structures. On this line, this manuscript aims to raise the efficiency of ECE by an optimal decision of the treatment setup concerning the electrolyte choice. Three different electrolytes were tested, namely, tap water, calcium hydroxide, and lithium borate. Experimental results pointed to lithium borate as the most efficient electrolyte for extracting chlorides while calcium hydroxide was a better choice to repassivate the structure and even heal cracks, due to a possible electrodeposition of the electrolyte ions on the cement matrix. Thus, depending on the main goal of the treatment, different electrolytes achieve a better performance, which highlights the importance of pretreatment evaluation to see in which stage of corrosion damage is the structure.
\end{abstract}

\section{Introduction}

Corrosion of reinforcing steel due to exposure to chloride leads to degradation of reinforced concrete structures. Dating from the early 60 's, electrochemical treatments raised as plausible options being nondestructive methods to prevent or/and recover corrosion of steel in concrete, by extracting aggressive agents such as chlorides or restoring alkalinity of concrete. Electrochemical chloride extraction (ECE) is one example, which is based on the mechanism of a direct current that flows through an anode fixed to the concrete surface, an alkaline electrolyte, and the reinforcing steel acting as the cathode, aiming the removal of chloride ions [1-4]. Figure 1 shows a schematic representation of the mechanisms and chemical reactions involved on ECE. The degree of chloride extraction is frequently measured by grinding the concrete cover, and it is mostly known to vary from 30 to $60 \%$ of removed chlorides depending on innumerous variables [5-18]. The setup to perform ECE has many particularities that can significantly affect its efficiency [7, 15-17]. Three major variables play an important role during the chloride removal process: the direct current, the electrolyte solution, and the external anode; therefore, the choice over them is of great importance and guidelines suggest some options, different from each other [19-21].

The chloride extraction rate is mostly measured considering the total concentration of ions in the bulk concrete, rather than chloride profiles at different depths of the cover concrete, although profiles may provide more direct and clear information on modified concentrations under electric charge, considering the penetration depths [20, 22-25]. Various externalities can easily influence the treatment, such as the environmental temperature during treatment [26], a high concrete resistance on site which decreases the efficiency of current passed, insufficient coverage of the anode, and arrangement of stirrups and steel rebars [19, 27, 28]. Due 


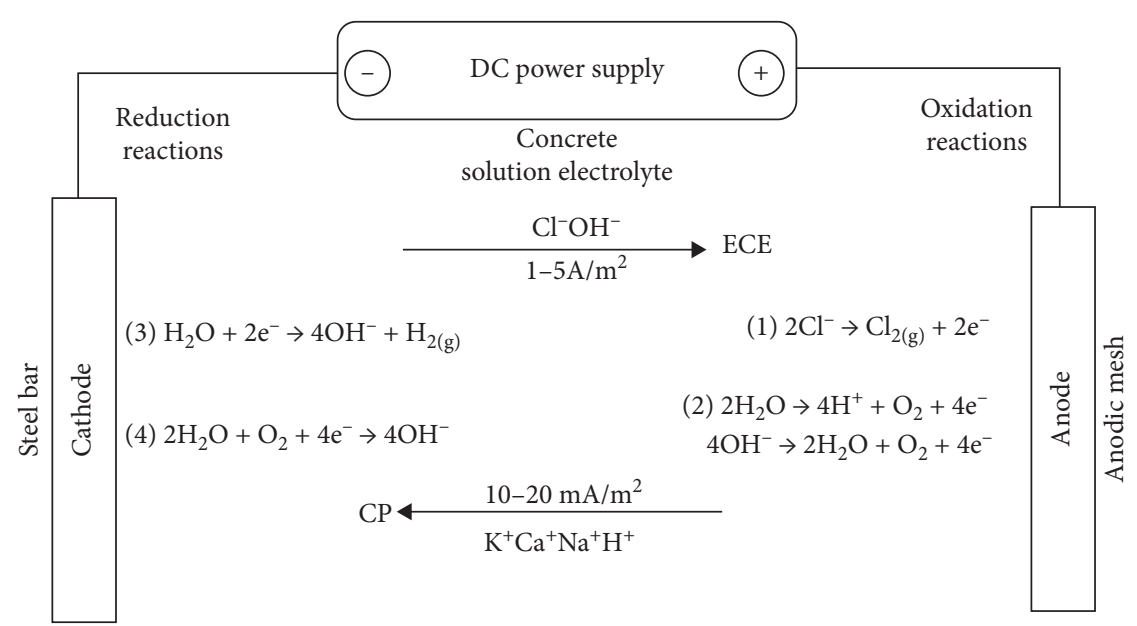

FIGURE 1: Mechanism of main electrochemical treatments and chemical reactions involved in the processes [6].

to that, different removal rates may occur at the same structural component, and results based only on the chloride extraction rate of the bulk concrete can be inconclusive.

Moreover, a change in the chloride mobility after ECE has been rarely taken into account. Chlorides are usually present in the cement matrix in the form of free and bound ones. Bound chlorides are divided into physically and chemically bound; the chemically bound is related to the reaction between chloride ions and $\mathrm{C}_{4} \mathrm{AF}$ or $\mathrm{C}_{3} \mathrm{~A}$, forming Friedel's salt, while physical binding is related to the adsorption of chloride ions to the C-S-H hydration products. For a certain time, it has been taken as a statement that only free chlorides impose the mobility in concrete, which would be the only type possibly removed by electric charge. However, the removal of bound chlorides in concrete under electric charge is being proposed by few authors up to date [15]. According to Sun [29], the majority of the physically bound chlorides can be easily extracted from C-S-H gel, by physical adsorption. An increased temperature can already accelerate the thermal vibration of absorbents releasing more free chlorides. In addition, some of chlorides adsorbed on the surface of hydrations are physically trapped in the unstable state and thus may be often mobilized by a strong driving such as the electromigration forces in ECE [30]. Chemically bound chlorides could achieve the mobility in concrete as well by acidification of the pore solution [31] and other modified environments of concrete.

On which concerns the setup of ECE, up to date, standards are still being elaborated around the world. For example, concerning electrolytes, SHRP-S-347 [32], the most common American guideline, indicates the usage of a borate-buffered electrolyte to avoid alkali silica reaction (ASR) during the process, while the European Standard [33] does not specify any solution, just mention that it should be alkaline, and the Norcure [34] patent suggests fresh water. Therefore, considering the lack of unified standards or guidelines pointing out the most efficient setup for ECE, in the present study, the chloride profile and chloride types for untreated and treated specimens were taken considering three different electrolytes, namely, tap water, calcium hydroxide, and lithium borate. Sodium chloride was added to the mixing water $\left(3 \% \mathrm{Cl}^{-}\right.$by mass of cement) to promote the corrosion onset from the beginning before applying the repair treatment. ECE was then applied at $2 \mathrm{~A} / \mathrm{m}^{2}$ for 4 weeks. The $\mathrm{pH}$ of electrolyte solution and voltage of the circuit were constantly monitored. The corrosion state was checked in terms of electrical potential, corrosion rate, and mass loss. The chloride profile was taken immediately after the completion of the treatment, differentiating acid soluble and water soluble chlorides to reflect the influence of chloride mobility under electrochemical treatment. Substantially, the change of chloride profiles after the treatment was interpreted paired with corrosion rate and corrosion potential measurements during treatment.

\section{Experimental Program}

The specimen preparation to investigate the chloride removal consists of casting the specimens, curing, and applying a DC. To reduce the possible influence of coarse aggregate on chloride distribution, mortar was used instead of concrete. The mixture proportions used in manufacturing the specimens for Ordinary Portland Cement: water: sand (Grade M) was 1.00:0.45:2.15. Table 1 shows the oxide composition of the binder. Sodium chloride was added to the mixing water $\left(3 \% \mathrm{Cl}^{-}\right.$by mass of cement) to promote the corrosion onset from the beginning before applying the repair treatment. Specimens were cast in a $150 \mathrm{~mm}$ cubic mold with a centrally located $10 \mathrm{~mm}$ diameter mild plain steel bar, containing 3 replications each to guarantee accuracy of results. The ends of the steel bars were masked off using a cementitious coating and then covered with heatshrink insulation to avoid corrosion under the masking material. The specimens were then cured for 28 days at $21 \pm 2^{\circ} \mathrm{C}$. After curing, the corrosion state of the rebar was evaluated by electrochemical techniques before treatment. Both the corrosion potential $\left(E_{\mathrm{corr}}\right)$ and polarization resistance $(\mathrm{Rp})$ were periodically obtained. The $\mathrm{Rp}$ was obtained by linear scan sweep from $-20 \mathrm{mV}$ to $+20 \mathrm{mV}$ versus $E_{\text {corr }}$ at $10 \mathrm{mV} /$ min. Applying the equation of Stern and Geary $[35,36]$, 
TABLE 1: Oxide composition of ordinary Portland cement used for the experimental work.

\begin{tabular}{lcccccccc}
\hline & \multicolumn{7}{c}{ Oxide composition (\%) } \\
Binder & $\mathrm{CaO}$ & $\mathrm{SiO}_{2}$ & $\mathrm{Al}_{2} \mathrm{O}_{3}$ & $\mathrm{FeO}$ & $\mathrm{MgO}$ & $\mathrm{SO}_{3}$ & Ignition loss (\%) & Fineness $\left(\mathrm{cm}^{2} / \mathrm{g}\right)$ \\
\hline OPC & 60.0 & 23.0 & 5.0 & 2.0 & 1.0 & 2.0 & 2.1 & 3120 \\
\hline
\end{tabular}

the corrosion current density $\left(i_{\text {corr }}\right)$ was obtained. Mean values are given for each sample.

The chloride extraction treatment was performed using an impressed current density of $2 \mathrm{~A} / \mathrm{m}^{2}$ of mortar surface for 4 weeks. Three types of electrolyte, namely, saturated $\mathrm{Ca}(\mathrm{OH})_{2}$, tap water, and lithium borate at 0.1 molar concentration were used. Mortars were treated after approximately only 28 days of curing, which is standard for most experiments, as an alternative to optimize the experimental schedule, considering that the main focus of the manuscript is given to the influence of electrolytes less than that to the microstructural changes. During the application of the electric charge, the specimens were immersed in an acrylic box filled with the different electrolytes, one at each time. A $15 \times 15 \mathrm{~cm}^{2}$ titanium mesh plate with a thickness of $2 \mathrm{~mm}$ was used as the external electrode (anode) and placed inside the acrylic box as well close to the concrete surface in all directions. A direct electric potential was applied from the regulator between the reinforcement bars and the external electrode. Voltage was accordingly increased up to $20 \pm 1 \mathrm{~V}$ in the beginning of the treatment to maintain the current density for 4 weeks. The total charge passed substantially accounted for $1344 \mathrm{Ah} / \mathrm{m}^{2}$. Figure 2 shows the experimental setup for applying the electrochemical chloride extraction to one specimen. The $\mathrm{pH}$ of the electrolyte solution and voltage of the circuit were constantly monitored to guarantee safety and efficiency of treatment as in Figure 3. After treatment was completed, specimens were removed from the acrylic box and kept in constant relatively humidity and temperature. To perform the corrosion measurements, the response of the rebars was periodically measured after 10 days (depolarization time) to evaluate the effectiveness of the treatment and the ability of repassivation of rebars according to different electrolytes.

To measure the chloride ion concentration, mortar powder was drilled from the specimens at the core obtaining dust samples. Specimens were ground by a diamond-grit plate from the surface in the direction of steel rebar at $1.0 \mathrm{~mm}$ first, next $5.0 \mathrm{~mm}$, and then at consecutives increments of $5.0 \mathrm{~mm}$ up to $2 \mathrm{~mm}$ of the cover depth. Samples were diluted in solvents to extract chloride ions. The chloride concentration in solution was obtained before and after treatment, determining the concentration of free, bound, and total chlorides at every depth. To avoid biased results on chloride concentration, dust samples were obtained at all 3 replications and their average value was taken. The chloride concentration was then determined for both water soluble and acid soluble chlorides. In fact, the water soluble chloride measured by the following method was regarded as free, whilst acid soluble as total. Simultaneously, the concentration of bound chlorides was determined by subtracting free from total values. On what concerns the measurement of water soluble chlorides, dust samples were diluted in $50^{\circ} \mathrm{C}$ distilled water and stirred for 3 minutes. After 30 minutes, the suspension was filtered using a paper filter. Then, the concentration of chloride ions was measured by the potentiometric titration against silver nitrate, and the values obtained are referred as free chlorides. Simultaneously, the sample was also used to determine the concentration of acid soluble chlorides by using on this turn distilled water and nitric acid. The obtained suspension was boiled for 1-2 minutes and filtered by the same paper filter, followed by cooling down to the ambient temperature and the titration against silver nitrate to determine the acid soluble chloride concentration, which are referred as total chlorides. Untreated specimens were used to measure the chloride profile immediately after curing, therefore making results for pretreatment.

\section{Results}

3.1. Chloride Removal Rates. Figures 4-6 illustrate the chloride concentration profiles before and after ECE process for the three different electrolytes which were determined in terms of total, free, and bound. As all specimens were mixed in same conditions, the initial levels of chlorides before treatment are similar for all cases and for free chlorides always above the chloride threshold at all levels, implying a high risk of corrosion. The concentration of chlorides at shallower depths is higher as it is expected, considering that the concentration near the core of the specimen hydration of cement is expected to be at a higher degree. From a first look at the figures, it is evident that the treatment was effective in extracting chloride ions for all cases at different extents. However, in all cases considering the total chlorides, the concentration at shallow depths (i.e. $<5.0 \mathrm{~mm}$ ) was less reduced as it is expected and may be attributed to a delayed dissolution of chlorides into the electrolytic solution after being transported to the surface of concrete during treatment. Due to the imbalance in ionic media between concrete substrate and liquid electrolyte, chloride ions could be intermittently present in the nearer surface. Moreover, the greater chloride content near the surface may be also attributed to the accumulation of chloride ions under the effect of migration, because chloride profiling was performed in the dry condition of concrete.

Figure 4 represents the results for tap water as an electrolyte, highlighting that three replications were used and the mean values are presented. Figure 4(a) shows that total chlorides before treatment ranged from $2.10-4.19 \%$ (by weight of cement) decreasing with the increase in depth. After treatment, the total chloride concentration was reduced to $1.35-3.20 \%$ at all depths, resulting on a percentage removal efficiency of $23.6-42.2 \%$ depending on the cover depth. Figure 4(b) represents the profiles for free chlorides before and after treatment. The concentration of free 


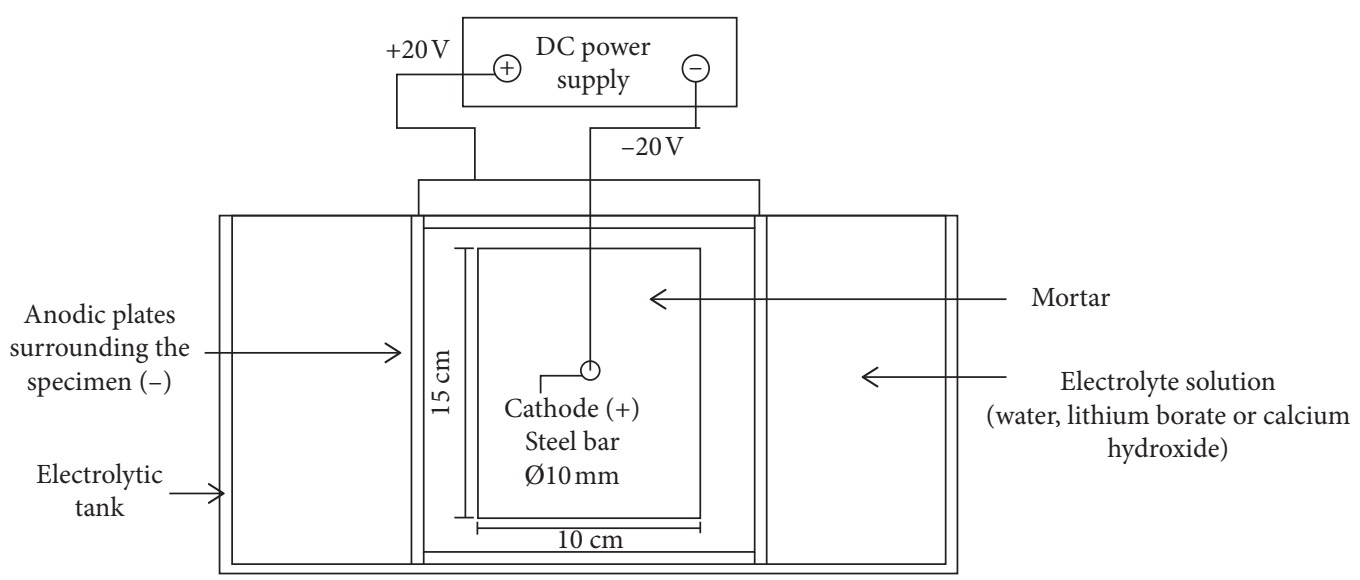

Figure 2: Schematic representation of the experimental setup for ECE using different electrolytes in aerial perspective. Each electrolytic tank contained 3 replications of each sample for better confidence of results.

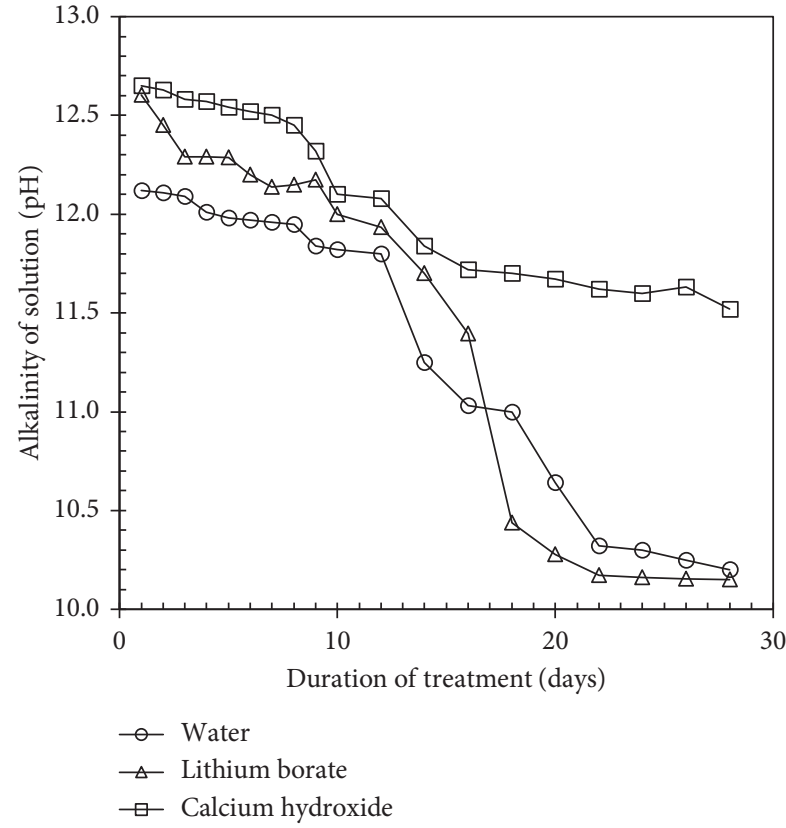

FIGURE 3: Electrolyte $\mathrm{pH}$ and voltage of circuit during treatment.

chlorides before treatment ranged from $0.75-1.89 \%$ by weight of cement, increasing for shallower depths. After treatment, the free chloride concentration was decreased at all depths accounting for $0.32-1.13 \%$ by weight of cement. It means that the treatment was efficient in this point as expected to remove free chlorides at levels lower than the chloride threshold to initiate corrosion. Figure 4(c) presents the results obtained for bound chlorides. The quantity of bound chlorides ranged from 1.35 to $2.30 \%$ by weight of cement in untreated specimens, while after treatment, a considerable reduction is perceived and the range of bound chlorides was limited distributed to about $0.96-1.87 \%$. It implies that bound chlorides were partially removed under electric field, and for that, they must have achieved some mobility. Moreover, for depths greater than $5.0 \mathrm{~mm}$, the residual bound chlorides converged to a continuous range of $1.37-1.87 \%$.
In turn, Figure 5 represents results calcium hydroxide as the electrolyte. Figure 5(a) shows that total chlorides before treatment ranged from $1.97-4.10 \%$ (by weight of cement) decreasing with the increase in depth. After treatment, the total chloride concentration was reduced from 1.20 to $3.00 \%$ at all depths, resulting on greater removal efficiency than it was found for tap water as the electrolyte. Figure 5(b) represents profiles for free chlorides before and after treatment. The concentration of free chlorides before treatment ranged from 0.72 to $1.77 \%$ by weight of cement, increasing for shallower depths, being above the chloride threshold at all levels as it was previously mentioned. After treatment, the free chloride concentration was decreased at all depths accounting for $0.23-0.97 \%$ by weight of cement, being more efficient than water in this case as well, removing free chlorides at levels lower than the chloride threshold to initiate corrosion. Figure 5(c) represents the results obtained for bound chlorides. The quantity of bound chlorides ranged from 1.26 to $2.33 \%$ by weight of cement in untreated specimens, while after treatment as it was seen for water, a considerable reduction is perceived and the range of bound chlorides was limited to about $0.83-1.78 \%$. Moreover, at increasing depths, the concentration of bound chlorides also converged to a specific range between 1.38 and $1.78 \%$.

Figure 6 represents the results obtained using lithium borate as electrolyte. Figure 6(a) shows that the concentration of total chlorides in the specimens initially ranged from 2.05-3.88\% (by weight of cement) at all depths. After treatment, these values were reduced to $0.88-2.86 \%$ depending on the cover depth. In particular, for this electrolyte, the sharpest reduction on total chloride level was obtained around $5.0 \mathrm{~mm}$ of the depth, where the residual chloride concentration accounted for only $1.15 \%$, whilst untreated specimen contained $2.95 \%$. For depths exceeding $5.0 \mathrm{~mm}$, the total chloride content was reduced into a similar range of values being around $0.88-1.00 \%$, being the most efficient removal among the three electrolytes. Figure 6(b) presents the profiles for free chlorides before and after treatment. The concentration of free chlorides was found to be in the range of $0.86-1.95 \%$ by weight of cement immediately after mixing, increasing for the shallower depths, 


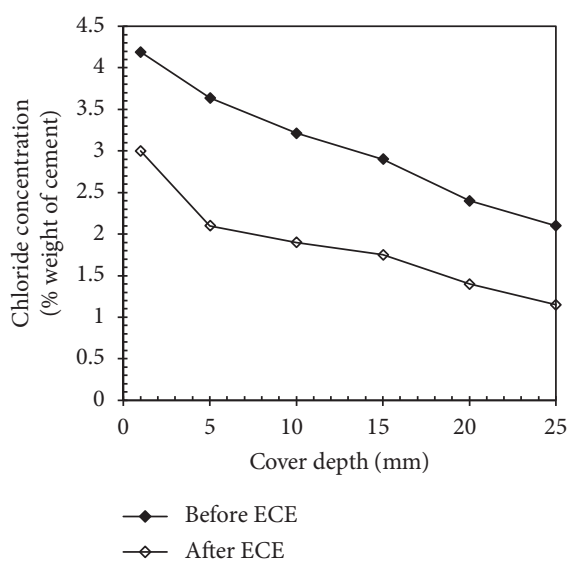

(a)

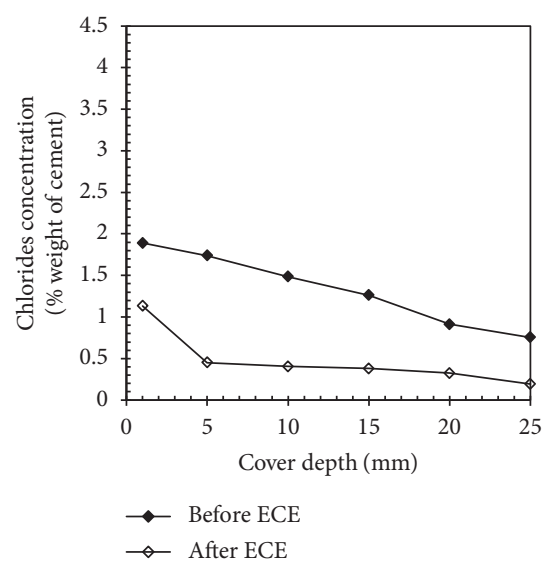

(b)

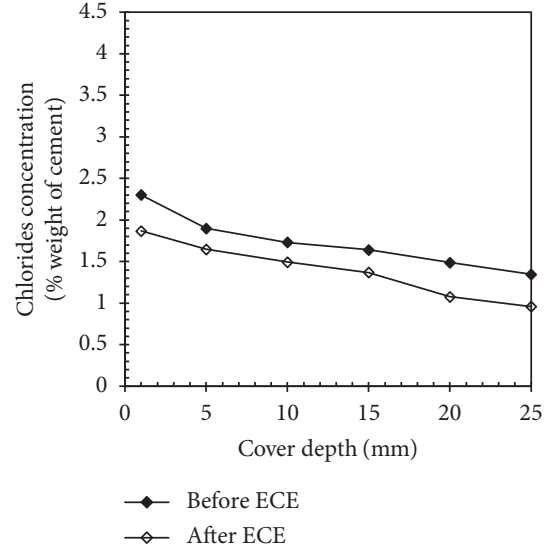

(c)

FIGURE 4: Chloride profiles before and after treatment using water as electrolyte for at $2 \mathrm{~A} / \mathrm{m}^{2}$ constantly for 4 weeks, in terms of (a) total*, (b) free**, and (c) bound ${ }^{* * *}$ chlorides. ${ }^{*}$ (a) Total: acid soluble titration against silver nitrate at the ambient temperature. ${ }^{* *}(\mathrm{~b})$ Free: water soluble chlorides dissolved in $50^{\circ} \mathrm{C}$ distilled water. ${ }^{* * *}(\mathrm{c})$ Bound: values obtained by subtracting the free chloride concentration from the total at each depth.

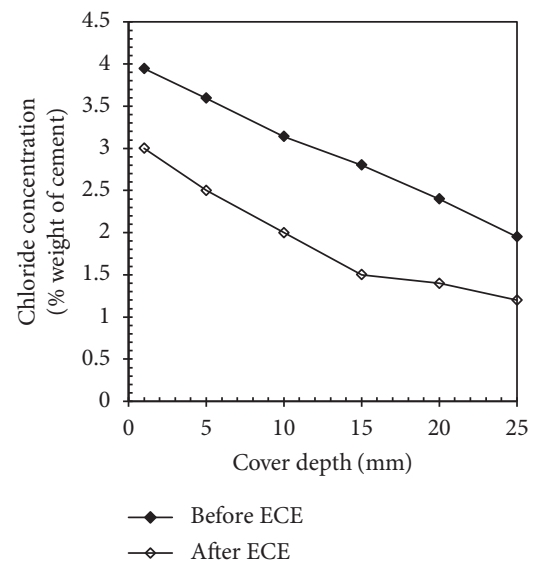

(a)

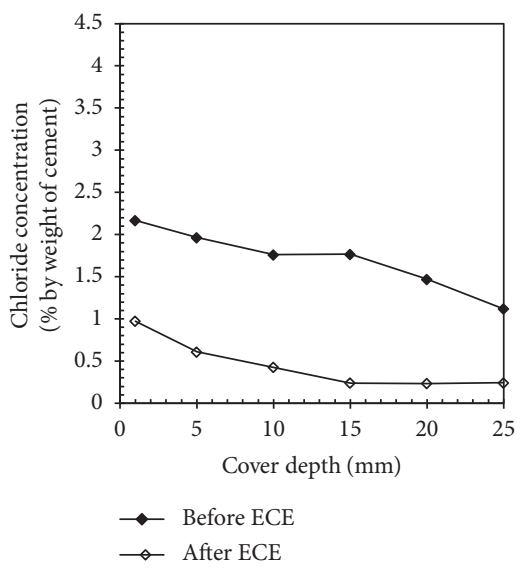

(b)

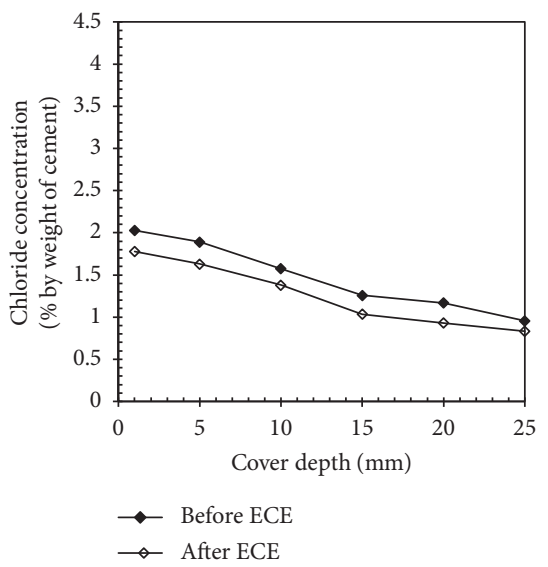

(c)

FIGURE 5: Chloride profiles before and after treatment using calcium hydroxide as electrolyte for at $2 \mathrm{~A} / \mathrm{m}^{2}$ constantly for 4 weeks, in terms of (a) total ${ }^{*}$, (b) free ${ }^{* *}$, and (c) bound ${ }^{* * *}$ chlorides. ${ }^{*}$ (a) Total: acid soluble titration against silver nitrate at the ambient temperature ${ }^{* *}$ (b) Free: water soluble chlorides dissolved in $50^{\circ} \mathrm{C}$ distilled water ${ }^{* * *}$ (c) Bound: values obtained by subtracting the free chloride concentration from the total at each depth.

above the chloride threshold. After treatment, the free chlorides concentration was sharply decreased almost to an insignificant level for all depths exceeding $5.0 \mathrm{~mm}$, accounting for less than $0.21 \%$ by weight of cement and less than $0.06 \%$ for depths exceeding $10.0 \mathrm{~mm}$. It means that treatment was the most efficient in this case and mostly free chlorides were in turn removed from concrete. At the surface of concrete $(<5.0 \mathrm{~mm})$, the concentration of free chloride was higher than that before treatment, ranging from 1.26 to $1.93 \%$, which is mainly due to the delayed dissolution of chloride ions in the electrolytic solution in the tank. However, the free chlorides at the nearer surface concrete could be easily removed by subsequently washing when the anodic system is removed, therefore imposing no risk of further corrosion process. Figure 6(c) presents the results obtained for bound chlorides. The quantity of bound chlorides ranged from 1.21 to $1.93 \%$ by weight of cement in untreated specimens, while after treatment, again the reduction is perceived and the range of bound chlorides was distributed to about $0.87-1.81 \%$ depending on the depth. For depths greater than $10.0 \mathrm{~mm}$, the residual bound chloride also converged to a limited range of $1.14-1.81 \%$. The removal of bound chlorides for all electrolytes contradicts the idea that only free chlorides may be mobile on the concrete pore solution. In addition, seeing that ECE is able to reduce the concentration of all chloride types, the risk of further corrosion is surely reduced, although the residual concentration for water and calcium hydroxide was still above the chloride threshold level for some depths.

Figure 7 summarizes the results for the chloride removal rates in percentage, making a direct comparison among all three electrolytes for each depth interval. In general, for 


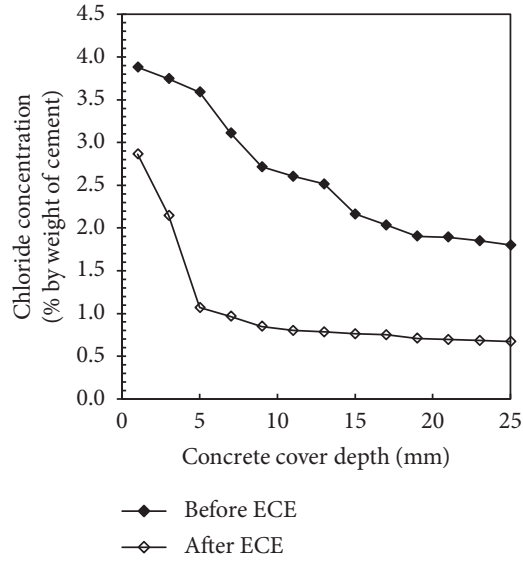

(a)

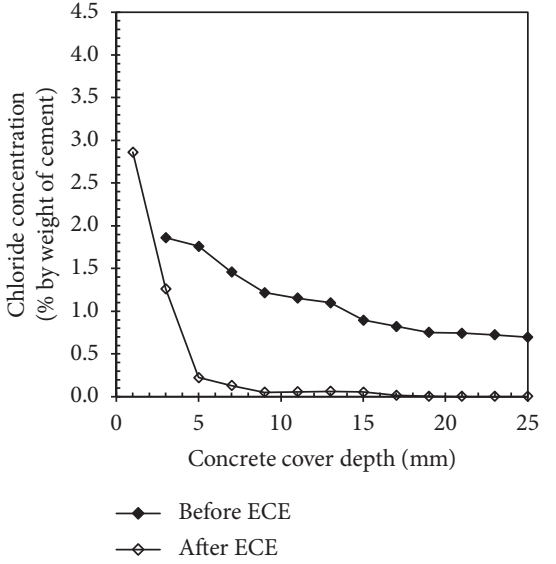

(b)

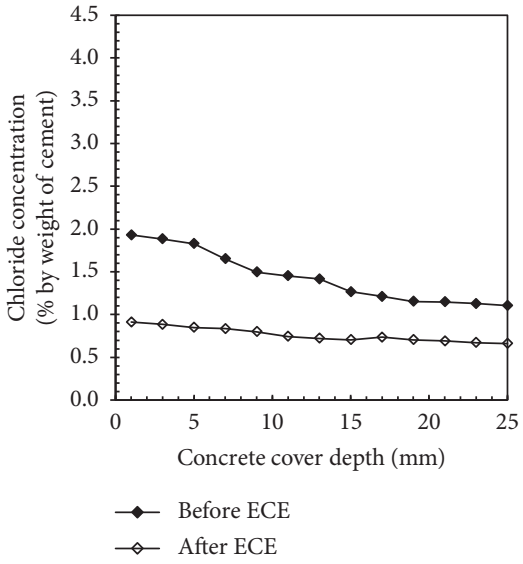

(c)

FIGURE 6: Chloride profiles before and after treatment using lithium borate as electrolyte for at $2 \mathrm{~A} / \mathrm{m}^{2}$ constantly for 4 weeks, in terms of (a) total $^{*}$, (b) free**, and (c) bound ${ }^{* * *}$ chlorides. ${ }^{*}$ (a) Total: acid soluble titration against silver nitrate at the ambient temperature. ${ }^{* *}(\mathrm{~b})$ Free: water soluble chlorides dissolved in $50^{\circ} \mathrm{C}$ distilled water. ${ }^{* * *}$ (c) Bound: value obtained by subtracting the free chlorides concentration from the total at each depth.

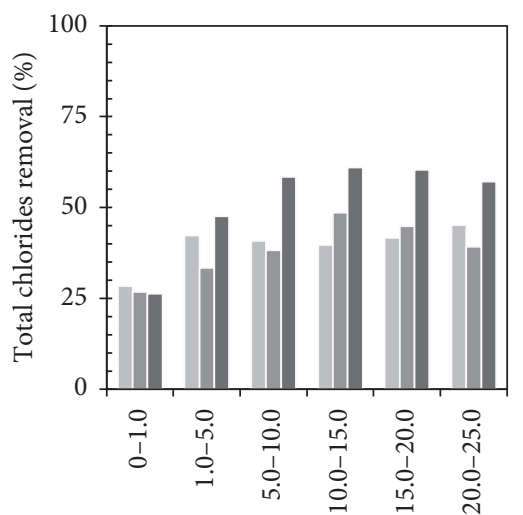

Cover depth (mm)

- Water

- Calcium hydroxide

- Lithium borate

(a)

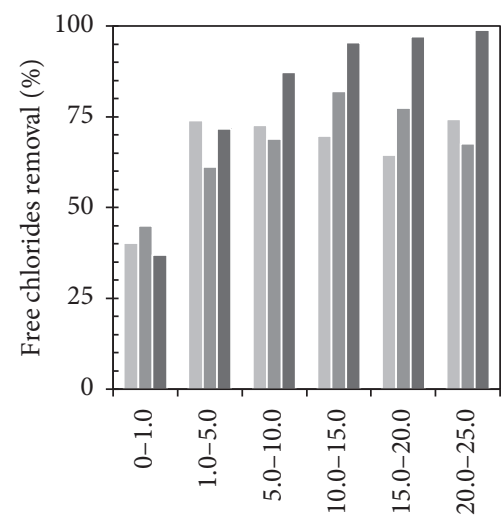

Cover depth $(\mathrm{mm})$

- Water

- Calcium hydroxide

- Lithium borate

(b)

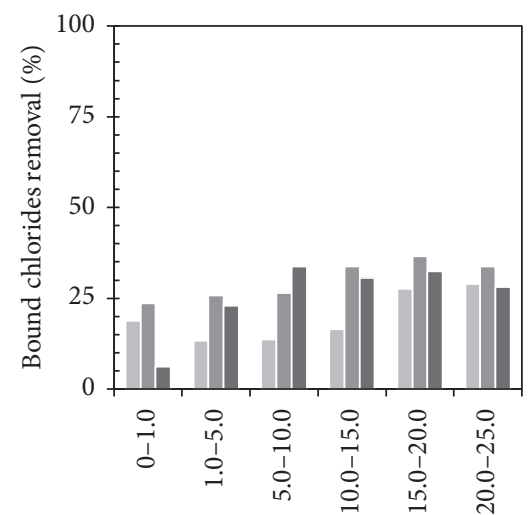

Cover depth $(\mathrm{mm})$

- Water

- Calcium hydroxide

- Lithium borate

(c)

FiguRE 7: Direct comparison on the efficiency on chloride removal for each designated cover depth in terms of (a) total, (b) free, and (c) bound chlorides.

lithium borate, a more expressive chloride removal is perceived for all chloride types. As it is shown in Figure 7(a), the removal efficiency of total chlorides ranged from 26.3-61.0\% depending on the cover depth, while for water and $\mathrm{Ca}(\mathrm{OH})_{2}$, the removal occurred at more similar values, resulting in percentage removal efficiencies of $23.6-42.2 \%$ and $26.7-48.6 \%$, respectively, showing only a slightly better performance of $\mathrm{Ca}(\mathrm{OH})_{2}$ but still not better than the first one. The chloride removal was always greater at increasing depths for reasons already mentioned. In Figure 7(b), taking into consideration only free chlorides, lithium borate again had a considerable better performance, accounting to a percentage removal efficiency of 36.9-98.8\%. For $\mathrm{Ca}(\mathrm{OH})_{2}$, the reduction occurred at significant amounts as well but not as efficiently, showing a percentage removal efficiency of $45 \%-82 \%$ depending on the cover depth. For tap water as the electrolyte, the free chloride removal was less significant, being the least efficient one. The concentration of free chlorides after treatment was reduced at a percentage removal efficiency of $40 \%-74 \%$ depending on the cover depth. On the same line, Figure 7(c) represents the direct comparison of results obtained for bound chlorides. A considerable removal could be perceived for all cases. In fact, different percentage removal was found for different electrolytes being the maximum of $28 \%$ for tap water as electrolyte, $36 \%$ for calcium hydroxide, and 33\% for lithium 
borate. The removal was slightly more significant at greater depths. The fact that, independent of the electrolyte, the efficiency in removing the bound chlorides is always similar may implicate that part of bound chlorides cannot be removed under any circumstance but cannot be turn into mobile neither, being stable and not participating on corrosion initiation.

\subsection{Corrosion Potential and Corrosion Rate. Concerning the} repassivation of the steel bar during treatment, the results are shown in Figure 8. Corrosion potential values at the beginning of treatment were nearly -700 to $-600 \mathrm{mV}$ vs. SCE for all cases as it can be seen in Figure 8(b), which implies that the steel bar was much corroded and had lost the passivity. The values were constantly monitored during treatment for all 3 different electrolytes and increased slowly during treatment, being the biggest increment between 1 and 3 weeks. At the end of treatment, values raised to $-293,-315$, and $-350 \mathrm{mV}$ vs. SCE for $\mathrm{Ca}(\mathrm{OH})_{2}$, water, and lithium borate, respectively, pointing to calcium hydroxide as a better option when considering repassivation after treatment and consequently protecting against further corrosion. Corrosion potential values are not yet on the passive condition (>-275 mV vs. SCE). However, as it was mentioned earlier in this paper, it seems inconclusive to analyze repassivation without a visual examination on the steel surface and without quantitative informative data such as corrosion rate or mass loss. Some authors [20, 21, 37] mentioned that it is not correct to rely in a fixed value to define if passivation is achieved by electrochemical treatment because many factors can influence that condition and ECE can induce more negative potentials of rebars because of strong polarization, meaning that readings one or two months after the end of treatment may show even a less negative potential than the one already achieved. In order to minimize the doubts about repassivation, a quantitative technique was used to ensure the corrosion state after ECE and measure the corrosion rate by linear polarization [38]. Results shown in Figure 8(a) pointed that the corrosion rate was significantly reduced by the electrochemical treatment. Before treatment, the values arose to around 500 to $1000 \mu \mathrm{A} /$ $\mathrm{cm}^{2}$ which points to highly corroded state of the steel rebar. By the end of treatment, the values were reduced to around 23, 286, and $107 \mu \mathrm{A} / \mathrm{cm}^{2}$ for $\mathrm{Ca}(\mathrm{OH})_{2}$, water, and lithium borate, respectively.

3.3. Visual Inspection and Mass Loss. In order to confirm visually and quantitatively the state of rebars after treatment, specimens were broken and the steel bar was removed. Figure 9 shows the rebars after ECE treatment and immersion in hydrochloric acid ( $\mathrm{HCl}$, sp. gr. 1.19) at $25^{\circ} \mathrm{C}$ for 2 hours to clean the rust. Bars were brushed in addition for better results. Results achieved from corrosion potential and corrosion rate could be confirmed visually, considering that rebars from specimens treated with $\mathrm{Ca}(\mathrm{OH})_{2}$ were in a considerable better state than the ones treated with water, where pit cracks can be easily seen. Table 2 summarizes the results. The backscattered mass loss for noncontaminated and noncorroded specimens accounted for around 0.017 to $0.034 \%$. For specimens treated with water, calcium hydroxide, and lithium borate, the percentual mass loss ranged from 1.37 to $1.63 \%, 0.39$ to $1.19 \%$, and 1.18 to $1.58 \%$, respectively. As it was expected, the specimens treated with water had the biggest percentage of mass loss which suggested a still more corroded state when compared with that of the other cases. Moreover, the visual examination confirmed the hypothesis that the steel bar was in a more alkaline environment for the specimens treated with the other two electrolytes.

\section{Discussions}

4.1. Removal of Bound Chlorides. At first, it is important to highlight for discussion that, independent of the electrolyte solution, bound chlorides were extracted at all depths. The presence of chlorides in the cement matrix is proved to be directly affected by some factors such as chemical properties of the pore solution, alkalinity, and hydration products. It is from common knowledge that, in concrete, chloride ions are usually divided into three types according to their stability: free, physically bound, and chemically bound. Chloride ions adsorbed or trapped to hydration products or chemically connected to other molecules such as for Friedel's salt are often regarded as "bound chlorides" and are originally regarded immobile in concrete at normal conditions (no acidification of the pore solution). On the other hand, free chloride ions have total mobility and can react easily to initiate the corrosion process, therefore being considered to be mainly responsible for a high risk of chloride-induced damage. Simultaneously, by having this high mobility, there is no doubt that free chloride ions tend to be mostly removed by electrochemical treatment, as it was proved by the experimental results exposed on this manuscript.

Chemically bound chlorides, which connect $\mathrm{C}_{3} \mathrm{~A}$ and $\mathrm{C}_{4} \mathrm{AF}$ molecules and form a compound referred as Friedel's salt, are unreactive and consequently immobile through the pore solution as long as the cement matrix is kept highly alkaline in the way it is supposed to be. However, the acidification of the pore solution in concrete may often occur at the pit nucleation on the surface of steel, when corrosion is taking place, accompanying a build-up of chloride ions. The acidification is explained, because during the corrosion initiation, $\mathrm{H}^{+}$ions might evolve in the vicinity of steel, which simultaneously react with chloride ions and produce hydrochloric acid [39-41]. According to Elsener and Angst [1], there are two main steps: most bound chloride is released at $\mathrm{pH}$ values lower than 12.5 and then another part is dissolved around $\mathrm{pH} 12$, suggesting that, at even lower $\mathrm{pH}$ values, nearly no bound chloride is left in the concrete. Consequently, part of these bound chlorides would be released and turned into free chlorides by $\mathrm{pH}$ fall which would take place in the vicinity of steel rather than in the concrete body.

Withal, according to the results shown by chloride profiles, bound chlorides were removed at all depths after electrochemical treatment and not only nearby the steel bar, which confirms that not only the chemically bound chlorides 


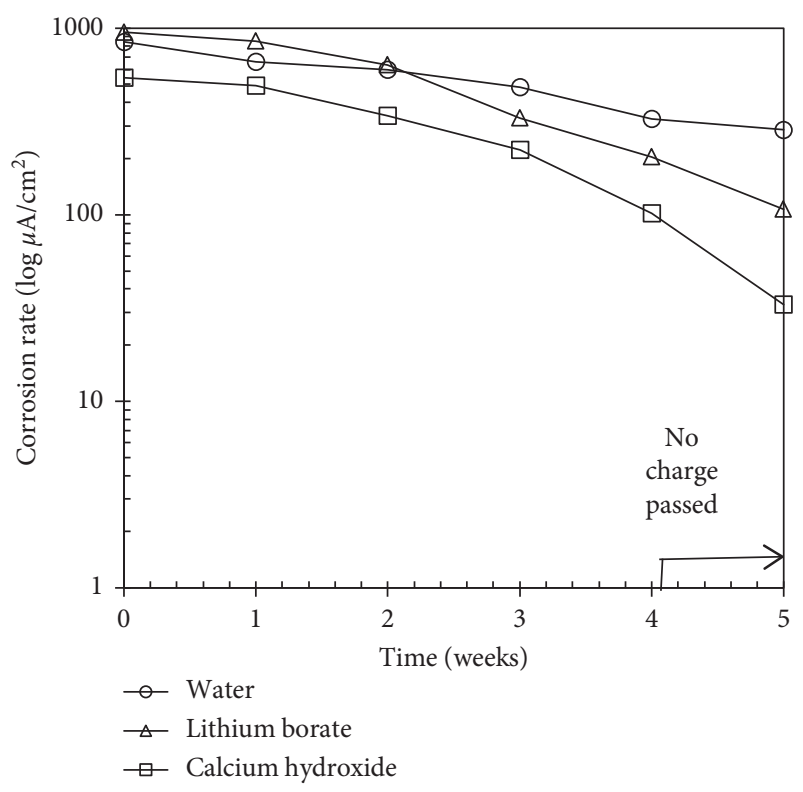

(a)

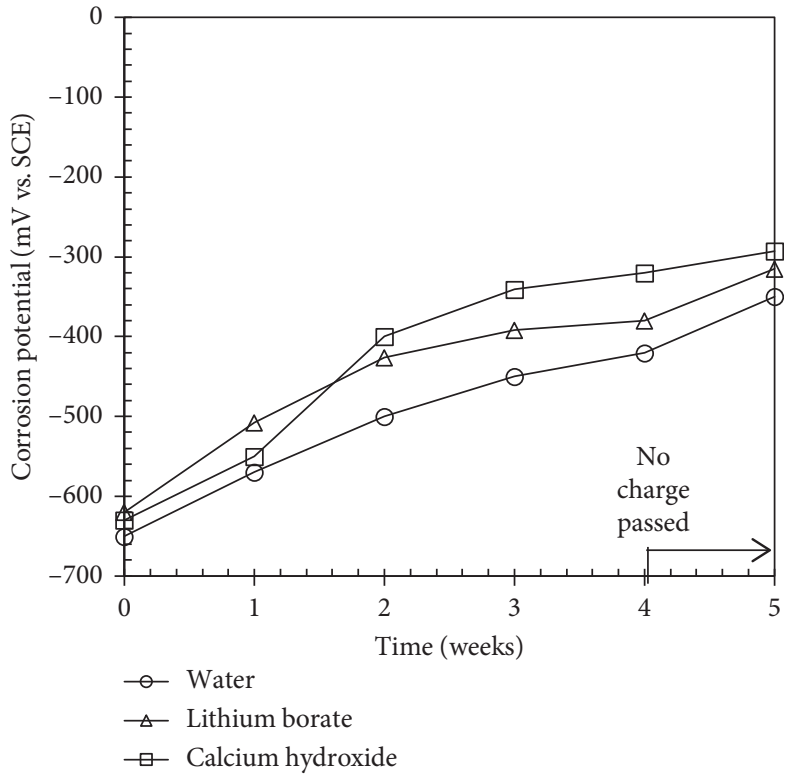

(b)

Figure 8: Corrosion values measured at each given charge passed during and after treatment* in terms of (a) corrosion rate** and (b) corrosion potential ${ }^{* * *}$. ${ }^{*}$ Posttreatment values are depicted in the highlighted area of the graph to show that no current was applied in that interval; measurements were performed at 5 weeks to ensure the quality of results after depolarization time. ${ }^{* *}$ (a) Corrosion rate values obtained by linear polarization at scan rate from $-20 \mathrm{mV}$ to $+20 \mathrm{mV}$ versus Ecorr at $10 \mathrm{mV} / \mathrm{min}$ and Stern and Geary equation. Mean values are given for each sample. ${ }^{* * *}$ (b) Corrosion potential values obtained by half-cell potential and the measurement of corrosion potential of rebar with respect to a saturated calomel electrode (SCE). Mean values are given for each sample.

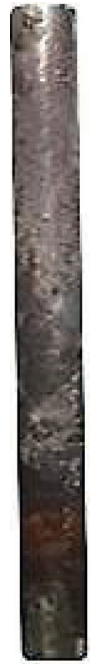

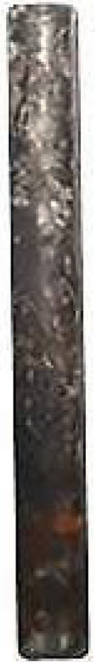

(a)
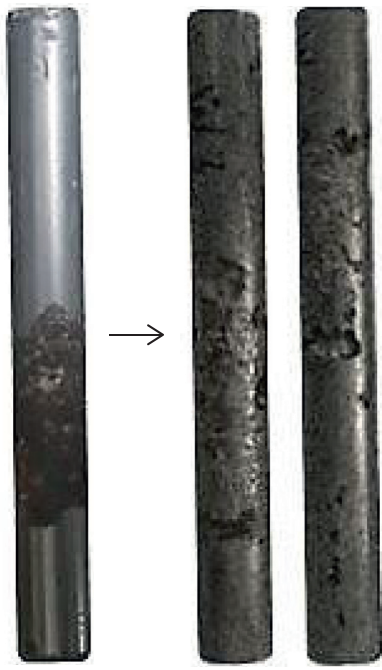

(b)

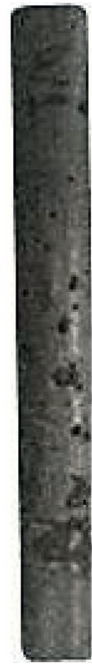

FIGURE 9: Visual aspect of bars after ECE treatment and immersion in hydrochloric acid $\left(\mathrm{HCl}\right.$, sp gr 1.19) at $25^{\circ} \mathrm{C}$ for 2 hours to clean the rust. Bars were brushed in addition for better results. The following cases depicted are in order from specimens treated with water, lithium borate, and calcium hydroxide, respectively, (a) right after treatment and (b) after rust cleaning.

were being released. Bound chlorides removed at farther depths from the steel bar may be the physically adsorbed ones that are usually adsorbed on the surface on the C-S-H gel or trapped between precipitated $\mathrm{Ca}(\mathrm{OH})_{2}$ molecules.
Physically bound chlorides can be easily released by changes on the environmental conditions, such as high temperature, that can accelerate the desorption process and turn them into free ones [42]. Substantially, the desorption of chloride ions could occur, despite of the acidification that affects the chemically bound chlorides, therefore being possible to occur at shallower depths. Furthermore, the removal of bound chlorides by electrochemical chloride extraction might be strongly dependent on the degree of chloride contamination in concrete [43], together with the applied current density and duration of the treatment, which may determine the driving force for free chloride ions and simultaneously affect the rate of decomposition for the bound ones.

4.2. Differences between Electrolytes for the Efficiency of Treatment. According to the results presented on the efficiency of the treatment on extracting chlorides, overall, lithium borate had the best performance followed by $\mathrm{Ca}(\mathrm{OH})_{2}$ and water. The smaller efficiency of calcium hydroxide might be explained by a process of electrodeposition of the electrolyte ions on pores of the cement matrix during treatment. The precipitation of certain ions on the concrete pores is proved from the late 80 's when the electrodeposition method was developed in Japan as a crack-repair treatment, where a direct current is provided between the reinforcing steel bar and an anode placed on the concrete surface, a system which is pretty similar to the one used for chloride removal [44]. The effectiveness of this method for crack 
TABLE 2: Results obtained by weighting the steel bars before and after treatment.

\begin{tabular}{lcccc}
\hline & Replications & Weight before casting (g) & Weight after treatment (g) & Percentual mass loss (\%) \\
\hline \multirow{2}{*}{ Control (backscattered loss) } & 1 & 58.05 & 58.04 & 0.017 \\
& 2 & 58.02 & 58.00 & 0.034 \\
Water & 3 & 58.03 & 58.01 & 0.034 \\
& 1 & 58.03 & 57.08 & 1.637 \\
\hline \multirow{2}{*}{ Calcium hydroxide } & 2 & 58.04 & 57.24 & 1.378 \\
& 3 & 58.02 & 57.09 & 1.603 \\
\hline \multirow{3}{*}{ Lithium borate } & 1 & 58.03 & 57.41 & 1.068 \\
& 2 & 58.05 & 57.35 & 0.930 \\
& 3 & 58.04 & 57.28 & 1.189 \\
\hline
\end{tabular}

repair in marine concrete structures is confirmed by several authors, and in several cases, calcium hydroxide is used. Therefore, during the electrochemical chloride removal process, the current applied probably induces the precipitation of $\mathrm{Ca}(\mathrm{OH})_{2}$ ions on pores of the cement matrix, blocking the network and reducing the mobility of chlorides ions, when compared with other electrolytes. Notwithstanding, tap water still showed a slightly lower efficiency, and that on the other hand may be explained simply by the fast acidification of the electrolyte and a constant need of replacement, which may obviously influence the treatment by reducing electromigration forces.

Moreover, electrodeposition may be also the factor to explain the better performance of calcium hydroxide to repassivate the structure after treatment. By filling up pores and consequently some possible cracks being caused by the corrosion process, a partial recovery on the repassivation of rebars could be achieved. Normally, the authors mention that the decrease of corrosion rate and partial recovery of half-cell potential are only related to the chloride removal, which are not the only reasons. The $\mathrm{pH}$ of the electrolyte solutions used during ECE and the voltage of circuit were monitored during the 4 weeks and are shown in Figure 3. After the first 2 weeks of treatment, there was a decrease in the $\mathrm{pH}$ of electrolytes. The $\mathrm{pH}$ reduction of electrolytes could be explained by the chlorine gas evolution, prevenient of the chlorides removed during treatment, if analyzed individually. However, for calcium hydroxide, the $\mathrm{pH}$ decrease was smaller and there was a significant increase in the voltage of the circuit, meaning an increase of concrete resistance. This shows that the $\mathrm{pH}$ fall may be additionally attributed to a migration of alkaline ions from the electrolyte solution to the concrete pore structure, being one more supporting factor to prove that electromigration happens during the electrochemical treatment. Thus, calcium hydroxide may not be the most efficient on removing chlorides, but it heals the structure at another level. In summary, depending on the main goal of the treatment, different electrolytes will show better performances, which also make it important to consider the pretreatment evaluation to see in which stage of corrosion damage the structure is.

\section{Conclusions}

In this study, ECE treatment was applied to mortar specimens containing sodium chloride added to the mixing water (3\% $\mathrm{Cl}^{-}$by mass of cement) to promote the corrosion onset from the beginning. ECE was applied at $2 \mathrm{~A} / \mathrm{m}^{2}$ for 4 weeks using three different electrolytes, namely, tap water, calcium hydroxide and lithium borate, while the $\mathrm{pH}$ of electrolyte solution and voltage of the circuit were constantly monitored. The chloride profile and chloride types for untreated and treated specimens were taken, and the change of chloride profiles after the treatment was interpreted paired with mass loss, corrosion rate, and corrosion potential measurements before and after treatment. The following conclusions were drawn from the experimental results:

(1) In general, for lithium borate, a more expressive chloride removal is perceived for all chloride types. The removal efficiency of total chlorides ranged from 26.3 to $61.0 \%$ depending on the cover depth, while for water and $\mathrm{Ca}(\mathrm{OH})_{2}$, the removal was lower and at similar rates, resulting on percentage removal efficiencies of $23.6-42.2 \%$ and $26.7-48.6 \%$, respectively. The chloride removal was always greater at increasing depths, due to the fact that, in the nearer surface, chlorides were quite present still in the process of diluting in the electrolyte media. As expected, free chlorides were removed at considerably high percentages for all cases, and lithium borate showed a considerable better performance, accounting to percentage removal efficiency up to $98.8 \%$. The concentration of bound chlorides was overall reduced by the electrochemical treatment, which challenges the hypothesis that all types of bound chlorides would be immobile under electric charge. The reduction of bound chlorides after the electrochemical treatment was hypothetically attributed to either a release of adsorbed chlorides by changes of physical factors or strong electromigration force or decomposition of Friedel's salt due to acidification of pore solution.

(2) Concerning the mass loss, corrosion potential, and corrosion rate readings, it can be said that ECE 
applied temporarily to the corroded concrete structure might be effective in only reducing the corrosion degree as the potential increased from nearly -700 to $-600 \mathrm{mV}$ vs. SCE for all cases to -293 , -315 , and $-350 \mathrm{mV}$ vs. SCE for $\mathrm{Ca}(\mathrm{OH})_{2}$, water, and lithium borate, respectively, pointing to calcium hydroxide as a better option when considering repassivation after treatment and consequent protection against further corrosion. In order to minimize the doubts about repassivation, a quantitative technique was also used to ensure the corrosion state after ECE and measure the corrosion rate by linear polarization. Results shown pointed that the corrosion rate was significantly reduced by the electrochemical treatment. Before treatment, values arose to around 500 to $1000 \mu \mathrm{A} / \mathrm{cm}^{2}$, and by the end of treatment, values were reduced to 23,286 , and $107 \mu \mathrm{A} / \mathrm{cm}^{2}$ for $\mathrm{Ca}(\mathrm{OH})_{2}$, water, and lithium borate, respectively, again pointing to $\mathrm{Ca}(\mathrm{OH})_{2}$ as the most efficient. Mass loss results and visual inspection confirmed the same statements.

(3) The partial repassivation in terms of the corrosion rate and half-cell potential can be explained due to the removal of chlorides and the migration of alkaline ions from the electrolyte to vicinity of the steel bar, on a process of electrodeposition. A supporting clause for this hypothesis is that, by measuring the $\mathrm{pH}$ of electrolyte solutions, for calcium hydroxide, the $\mathrm{pH}$ decrease was smaller and there was a significant increase on the voltage of the circuit, meaning an increase of concrete resistance. This shows that the $\mathrm{pH}$ fall may be additionally attributed to a migration of alkaline ions from the electrolyte solution to the concrete pore structure. By filling up pores and consequently some possible cracks caused by the corrosion process, a partial recovery on the repassivation of rebars could be achieved. Moreover, the same factor can explain a lower performance of calcium hydroxide on chloride removal, because during the electrochemical chloride removal process, the current applied probably induces the precipitation of $\mathrm{Ca}(\mathrm{OH})_{2}$ ions on pores of the cement matrix, blocking the network and reducing the mobility of chlorides ions, when compared with that of other electrolytes.

(4) Considering different electrolytes, lithium borate appeared to be the most efficient to extract chlorides from concrete while calcium hydroxide has better performance on restoring the passive state after corrosion, healing the structure at another level, filling up possible cracks as well. Therefore, in summary, depending on the main goal of the treatment, different electrolytes will show better performances, which also make it important to consider the pretreatment evaluation to see in which stage of corrosion damage is the structure. This also highlights the need of better specifications on standards and guidelines about the treatment setup.

\section{Data Availability}

The data used to support the findings of this study are included within the article.

\section{Conflicts of Interest}

The authors declare no conflicts of interest.

\section{Acknowledgments}

This work was supported by the National Research Foundation of Korea (Grant number: 2020R1A2C3012248).

\section{References}

[1] B. Elsener and U. Angst, "Mechanism of electrochemical chloride removal," Corrosion Science, vol. 49, no. 12, pp. 4504-4522, 2007.

[2] B. Elsener, M. Molina, and H. Böhni, "The electrochemical removal of chlorides from reinforced concrete," Corrosion Science, vol. 35, no. 5-8, pp. 1563-1570, 1993.

[3] J. Meitz, Electrochemical Rehabilitation Methods for Reinforced Concrete Structures: A State of the Art Report, The Institute of Materials Minerals and Mining, London, UK, 1998.

[4] U. M. Angst, M. R. Geiker, A. Michel et al., "The steel-concrete interface," Materials and Structures, vol. 50, no. 2, p. 143, 2017.

[5] N. M. Ihekwaba, B. B. Hope, and C. M. Hansson, "Carbonation and electrochemical chloride extraction from concrete," Cement and Concrete Research, vol. 26, no. 7, pp. 1095-1107, 1996.

[6] T. D. Marcotte, C. M. Hansson, and B. B. Hope, "The effect of the electrochemical chloride extraction treatment on steelreinforced mortar part II: microstructural characterization," Cement and Concrete Research, vol. 29, no. 10, pp. 1561-1568, 1999.

[7] C. Arya, Q. Sa'id-Shawqi, and P. R. W. Vassie, "Factors influencing electrochemical removal of chloride from concrete," Cement and Concrete Research, vol. 26, no. 6, pp. 851-860, 1996.

[8] N. M. Ihekwaba, B. B. Hope, and C. M. Hansson, "Pull-out and bond degradation of steel rebars in ECE concrete," Cement and Concrete Research, vol. 26, no. 2, pp. 267-282, 1996.

[9] N. R. Buenfeld and J. P. Broomfield, "Influence of electrochemical chloride extraction on the bond between steel and concrete," Magazine of Concrete Research, vol. 52, no. 2, pp. 79-91, 2000.

[10] E. Otero, J. A. González, A. Cobo, and M. N. González, "Electrochemical chloride removal from reinforced concrete structures and its ability to repassivate prerusted steel surfaces," Materials and Corrosion, vol. 52, no. 8, pp. 581-589, 2001.

[11] S. R. Sharp, G. G. Clemena, V. P. Virmani, G. E. Stoner, and R. G. Kelly, "Electrochemical chloride extraction: influence of concrete surface on treatment," Report no. FHWA-RD-02107, Diane Publishing Company, Darby, PA, USA, 2002.

[12] R. B. Polder, "Laboratory investigation of electrochemical chloride extraction from concrete with penetrated chloride," Heron, vol. 47, 2002.

[13] J. C. Orellan, G. Escadeillas, and G. Arliguie, "Electrochemical chloride extraction: efficiency and side effects," Cement and Concrete Research, vol. 34, no. 2, pp. 227-234, 2004. 
[14] A. Hosseini and A. R. Khalou, "Study of electrochemical chloride extraction as a non-destructive repair method: part I. Discrete test samples," Asian Journal of Civil Engineering (Building and Housing), vol. 6, pp. 167-182, 2005.

[15] M. J. Sanchez, P. Garces, and M. A. Climent, "Electrochemical extraction of chlorides from reinforced concrete: variables affecting treatment efficiency," Materials de Construccion, vol. 56, pp. 17-26, 2006.

[16] J. M. Miranda, J. A. González, A. Cobo, and E. Otero, "Several questions about electrochemical rehabilitation methods for reinforced concrete structures," Corrosion Science, vol. 48, no. 8, pp. 2172-2188, 2006.

[17] Y. Tissier, V. Bouteiller, E. Marie-Victoire, S. Joiret, T. Chaussadent, and Y. Tong, "Electrochemical chloride extraction to repair combined carbonated and chloride contaminated reinforced concrete," Electrochimica Acta, vol. 317, pp. 486-493, 2019.

[18] H. Lin and Y. Li, "A study on the deterioration of interfacial bonding properties of chloride-contaminated reinforced concrete after electrochemical chloride extraction treatment," Construction and Building Materials, vol. 197, pp. 228-240, 2019.

[19] C. C. Chang, W. Yeih, J. J. Chang, and R. Huang, "Effects of stirrups on electrochemical chloride removal efficiency," Construction and Building Materials, vol. 68, pp. 692-700, 2014.

[20] I. Martinez, F. Rozas, S. Ramos-Cillan, M. González, and M. Castellote, "Chloride Electroremediation in reinforced structures: preliminary electrochemical tests to detect the steel repassivation during the treatment," Electrochimica Acta, vol. 181, pp. 288-300, 2015.

[21] I. Martínez, M. González, F. Rozas, and M. Castellote, "New non-destructive passivity indicators for the control of electrochemical chloride extraction in concrete," in Proceedings of the CORROSION 2014, San Antonio, TX, USA, March 2014.

[22] M. Sánchez and M. C. Alonso, "Electrochemical chloride removal in reinforced concrete structures: improvement of effectiveness by simultaneous migration of calcium nitrite," Construction and Building Materials, vol. 25, no. 2, pp. 873878, 2011.

[23] A. Pérez, M. A. Climent, and P. Garcés, "Electrochemical extraction of chlorides from reinforced concrete using a conductive cement paste as the anode," Corrosion Science, vol. 52, no. 5, pp. 1576-1581, 2010.

[24] A. Cañón, P. Garcés, M. A. Climent, J. Carmona, and E. Zornoza, "Feasibility of electrochemical chloride extraction from structural reinforced concrete using a sprayed conductive graphite powder-cement paste as anode," Corrosion Science, vol. 77, pp. 128-134, 2013.

[25] K. B. Kim, J. P. Hwang, and K. Y. Ann, "Influence of cementitious binder on chloride removal under electrochemical treatment in concrete," Construction and Building Materials, vol. 104, pp. 191-197, 2016.

[26] J. Xia, Q.-f. Liu, J.-h. Mao et al., "Effect of environmental temperature on efficiency of electrochemical chloride removal from concrete," Construction and Building Materials, vol. 193, pp. 189-195, 2018.

[27] J. Xia, X. Cheng, Q.-f. Liu et al., "Effect of the stirrup on the transport of chloride ions during electrochemical chloride removal in concrete structures," Construction and Building Materials, vol. 250, Article ID 118898, 2020.

[28] W. Yeih, J. J. Chang, C. C. Chang, K. L. Chen, and M. C. Chi, "Electrochemical chloride removal for reinforced concrete with steel rebar cage using auxiliary electrodes," Cement and Concrete Composites, vol. 74, pp. 136-146, 2016.
[29] W. Sun, "Study on the influence of chloride ions content on the sea sand concrete performance," American Journal of Civil Engineering, vol. 4, no. 2, pp. 50-54, 2016.

[30] H. W. Song, M. S. Jung, C. H. Lee, S. H. Kim, and K. Y. Ann, "Influence of chemistry of chloride ions in cement matrix on corrosion of steel," ACI Materials Journal, vol. 107, pp. 332339, 2010

[31] G. K. Glass, A. M. Hassanein, and N. R. Buenfeld, "Cathodic protection afforded by an intermittent current applied to reinforced concrete," Corrosion Science, vol. 43, no. 6, pp. 1111-1131, 2001.

[32] J. Bennett and T. J. Schue, Chloride Removal Implementation Guide, SHRP-S-347, National Research Council, Washington, DC, USA, 1993.

[33] DD CEN/TS 14038-2, Electrochemical Realkalisation and Chloride Extraction Treatments for Reinforced Concrete Part2: Chloride Extraction, AFNOR, Paris, France, 2011.

[34] J. Bennett and T. J. Schue, Evaluation of Norcure Process for Electochemical Chloride Removal from Steel-Reinforced Concrete Bridge Components (No. Shrp-C-620), 1993.

[35] H. H. Uhlig and C. V. King, "Corrosion and corrosion control," Journal of the Electrochemical Society, vol. 119, no. 12, p. 327C, 1972.

[36] J. A. González and C. Andrade, "Effect of carbonation, chlorides and relative ambient humidity on the corrosion of galvanized rebars embedded in concrete," British Corrosion Journal, vol. 17, no. 1, pp. 21-28, 1982.

[37] B. Elsener, "Half-cell potential mapping to assess repair work on RC structures," Construction and Building Materials, vol. 15, no. 2-3, pp. 133-139, 2001.

[38] T. Y. Hao, "Study on the variation of electric potential in reinforced concrete members during accelerated corrosion and electrochemical chloride extraction process," IOP Conference Series: Materials Science and Engineering, IOP Publishing, vol. 479, no. 1, Bristol, UK, 2019.

[39] K. Y. Ann, Enhancing the chloride threshold level for steel corrosion in concrete, Ph.D. thesis, University of London, London, UK, 2005.

[40] H. W. Song, C. H. Lee, M. S. Jung, and K. Y. Ann, "Development of chloride binding capacity in cement pastes and influence of the $\mathrm{pH}$ of hydration products," Canadian Journal of Civil Engineering, vol. 35, no. 12, pp. 1427-1434, 2008.

[41] G. K. Glass, B. Reddy, and N. R. Buenfeld, "The participation of bound chloride in passive film breakdown on steel in concrete," Corrosion Science, vol. 42, no. 11, pp. 2013-2021, 2000.

[42] C. Arya, N. R. Buenfeld, and J. B. Newman, "Assessment of simple methods of determining the free chloride ion content of cement paste," Cement and Concrete Research, vol. 17, no. 6, pp. 907-918, 1987.

[43] J. S. Ryou and K. Y. Ann, "Variation in the chloride threshold level for steel corrosion in concrete arising from different chloride sources," Magazine of Concrete Research, vol. 60, no. 3, pp. 177-187, 2008.

[44] J. S. Ann and P. Monteiro, "Electrodeposition as a rehabilitation method for concrete materials," Canadian Journal of Civil Engineering, vol. 31, no. 5, pp. 776-781, 2004. 